Ann. Zootech., I977, 26 (2), 207-228.

\title{
Données complémentaires sur les besoins de la poule reproductrice naine Vedette I.N.R.A. (JV 15) en énergie et acides aminés
}

\author{
J. GUILLAUME \\ avec la collaboration technique de Liliane Derovet et Joëlle Gomez \\ Station de Recherches avicoles, \\ Centre de Recherche de Tours, I.N.R.A., \\ Nonzilly 37380 Monnaie (France)
}

\begin{abstract}
Résumé
Nous effectuons trois expériences sur la poule reproductrice lourde nanifiée Vedette I.N.R.A. JV i $5(d w)$. Tous les animaux sont élevés en batteries sur une durée relativement courte $(5$ à 8 périodes de 4 semaines), nourris et contrôlés individuellement. Un autre essai porte sur des poules issues d'un croisement coq hétérozygote $\times$ poule naine où $50 \mathrm{p}$. I oo des poules sont normales et 50 p. I oo naines. On étudie l'influence du rationnement subi par les poulettes durant leur croissance et celui de la taille corporelle au moment de l'entrée en ponte. On recherche en outre les influences des consommations d'énergie, méthionine et lysine sur les performances. Les poules lourdes réagissent différemment des poules légères à une carence en énergie (on observe une réduction du poids et du nombre des ceufs chez les sujets lourds, une réduction du poids seulement chez les sujets légers); les interactions entre facteurs alimentaires et taille corporelle sont cependant négligeables; on peut donc considérer que le rationnement de la poulette, dans les limites considérées, ne modifie pas les besoins alimentaires durant la période de ponte. L'effet de la carence en lysine s'avère plus tardif que celui de la carence en méthionine. L'ingestion de doses de méthionine dépassant $320 \mathrm{mg}$ /animal et par jour a toujours des effets bénéfiques, mais ceux-ci varient d'un essai à l'autre : on observe, soit une augmentation des performances durant les 8 premières semaines de ponte seulement, soit une augmentation durable concernant le poids moyen de l'cuf. La supplémentation du régime maternel en méthionine améliore en outre le poids moyen des poussins à l'éclosion. Par ailleurs, l'effet de la supplémentation en méthionine est beaucoup plus net chez les poules les plus carencées en énergie. Bien que le besoin soit, de ce fait, difficile à définir, on peut recommander des doses de l'ordre de 360 à $380 \mathrm{mg} / \mathrm{j}$. Dans nos conditions le besoin en énergie est de $320 \mathrm{kcal}$ et le besoin en lysine est très voisin de $750 \mathrm{mg} / \mathrm{j}$. I.e rôle propre du gène $d w$ sur ces besoins, et en particulier sur le besoin en méthionine, est discuté.
\end{abstract}




\section{Introduction}

Les poules reproductrices nanifiées, porteuses du gène récessif et lié au sexu $d w$ (HuTt, I949, I959) connaissent actuellement un succès croissant dû à leurs excellentes performances (RICARD, I974). Toutefois, les données scientifiques sur les besoins alimentaires de ce type d'animaux sont rares : LeclercQ, Guiliaume et BLUM, I970 ont montré que la reproductrice naine Vedette I.N.R.A. JV I5 n'avait pas besoin d'être nourrie avec un régime très riche en protéines comme c'est le cas de la Leghorn $d w$ (Arscott et Bernier, I968). Les résultats de Leclerco, Guillaume et Blum, I970, Guillaume i972a permettaient de situer le besoin énergétique des oiseaux utilisés aux alentours de $300-320 \mathrm{kcal} \mathrm{E.M./j}$. tandis que le besoin en protéines équilibrées est voisin de 16 à I $8 \mathrm{~g} / \mathrm{j}$.

Ces données paraissaient cependant insuffisantes pour élever de façon rationnelle cette reproductrice naine : le besoin en énergie n'était que grossièrement situé; le besoin en acides aminés essentiels le plus souvent limitants (acides aminés soufrés et lysine) n'était pas précisé; on igncrait si le rationnemert durant la croissance, qui s'avère extrêmement utile pour la rentabilité de l'élevage (LecLercQ et BLUM, I972, I973, I975) modifiait ces besoins; par ailleurs on. pouvait se demander si l'amélioration génétique du croisement considéré (Vedette I.N.R.A. JV I5), en augmentant le poids corporel, n'avait pas quelque peu modifié les besoins depuis l'époque où l'on avait effectué les premières expériences de nutrition. Trois expériences sur poules en batteries sont donc effectuées dans le but de préciser ces points.

\section{Matériel et méthodes}

Toutes les expériences sont effectuées sur des poules de croisement JV I5 (Vedette I.N.R.A. lourde) provenant d'un couvoir commercial; seul l'essai n ${ }^{\circ} 3$ porte pour moitié sur des poules JV I5 et pour moitié sur des poules provenant d'un croisement expérimental Dwdw $\times \mathrm{DW}^{-}$ò̀ les mâles sont des frères de la femelle naine JA 57 et les femelles sont des pondeuses d'œufs de consommation de type Rhode Island Red (Warren Studler). Des femelles de ce même croisement ont également été utilisées dans l'essai décrit par LECLERCQ et BLUM, I975.

Dans les trois essais les poules sont élevées en batteries de cages individuelles sur une période relativement courte. Le bâtiment est de type obscur; l'éclairage est de I4 h par jour au début de chaque essai, puis il est augmenté de I $5 \mathrm{mn}$ par quinzaine à partir du $\mathrm{I}^{\mathrm{er}}$ mois suivant le pic de ponte. Comme dans les essais antérieurs (Leclerco, Guillaume et Blum, i97o; Guillaume, i972a) chaque poule est rourrie individucllement. Le nombre et le poids de tous les œufs sont contrôlés. Chaque essai est subdivisé en périodes de 28 jours. Les critères retenus pour chaque période sont les suivants : intensité de ponte $\left(\frac{\text { nombres d'cufs pondus }}{\text { somme du nombre te poules vivantes chaque jour }}\right)$, poids moyen de l'œuf, poids d'œufs pondus, consommation alimentaire, indice de consommation rapporté au nombre et au poids des œufs produits, les six dernières variables sont calculées sur l'ensemble des poules vivant et pondant durant la période considérée (I);

(I) Nous avons préféré, pour les calculs autres que l'intensité de ponte, éliminer les poules ne pondant pas plutôt que d'estimer le poids moyen de leur óuf à l'aide de celui des pétiodes précédentes. Cette élimination supprime également les indices de consommation infinis. 
durant la totalité de l'essai on calcule en outre, la mortalité, le poids et l'augmentation du poids des animaux.

Les protocoles précis de chaque essai sont les suivants :

\section{Essai I (I970-I972)}

Cet essai est destiné à vérifier l'influence du poids corporel et du rationnement pendant la croissance sur les besoins quotidiens de la poule en nutriments et en particulier les besoins énergétiques.

Pour cela on élève des poulettes ad libitum jusqu'à 6 semaines. Puis on les subdivise en deux groupes élevés dans des locaux différents : les unes sont rationnées selon le programme recommandé par le sélectionneur (SELAF — I.N.R.A.); les autres sont rationnées de manière plus sévère (distribution de $83,3 \mathrm{p}$. roo de la dose allouée au I er lot). L'aliment utilisé pendant toute la période d'élevage de ces poulettes a une composition constante, il contient i 8 p. Ioo de protéines brutes et apporte $2800 \mathrm{kcal}$ E.M. $/ \mathrm{kg}$.

A I7 semaines, 468 poulettes sont mises en expérience selon le protocole suivant : dans chacun des 2 groupes, 234 poulettes sont réparties en 3 classes (légères, moyennes et lourdes). Les poulettes sont alors mises en batterie selon un dispositif en blocs casualisés. Chacun des 78 blocs comprend 6 poulettes d'un même groupe appartenant à une même classe de poids qui sont placées côte à côte sur un même étage de la batterie et qui reçoivent chacune un régime différent. Chacun des 6 régimes est alors distribué à 78 poules.

On compare 6 régimes dérivant des 3 formules détaillées dans le tableau I. Tous apportent I 7 p. roo de protéine brute environ et un minimum de 0,30 p. Ioo de méthionine $(0,64 \%$ d'acides aminés soufrés) et 0,73 p. Ioo de lysine. Le niveau énergétique des aliments $I$ et $x M, 2$ et $2 M, 3$ et $3 M$ est évalué par calcul à 2675 , 2885 et $3095 \mathrm{kcal}$ E.M. par kg respectivement (le niveau réel étant mesuré sur coqs adultes selon la méthode du ramassage total). Les régimes I M, $2 \mathrm{M}$ et $3 \mathrm{M}$ dérivent des régimes I, 2 et 3 respectivement par le remplacement de 0,15 p. Ioo de cellulose par o, I5 p. Ioo de DL méthionine, soit 23 p. Ioo de l'apport d'acides aminés soufrés recommandé pour les pondeuses d'œufs de consommation par l'A.E.C. (Anonyme, 1972). Tous les animaux reçoivent une même ration d'aliment, mesurée, la quantité d'énergie ingérée est à peu près proportionnelle au niveau énergétique $\mathrm{du}$ régime (les refus étant peu importants). La ration allouée qui était de 56 à $60 \mathrm{~g}$ à 20 semaines (rationnement "sévère " et "selon les normes ") est amenée en 2 semaines à I $05 \mathrm{~g}$ ce qui correspond à 280,305 et $325 \mathrm{kcal} \mathrm{E.M./jour} \mathrm{pour} \mathrm{les}$ lots I et I M, 2 et $2 \mathrm{M}, 3$ et $3 \mathrm{M}$ respectivement.

Un essai de croissance est effectué sur des poussins issus de lots de $5^{\circ}$ poules choisies parmi les 78 recevant chacun des 6 régimes pendant la $5^{\mathrm{e}}$ période de ponte. Pour cela on insémine les poules avec du sperme de coqs de type Cornish et, 2 jours après, on récolte les cufs pendant une semaine; on conserve ensuite un poussin mâle et un poussin femelle de $\mathrm{I} 2$ poules de chaque combinaison régime $x$ classe de poids. Ces poussins ( 72 par régime maternel) sont élevés en batterie par lots de $\mathrm{I} 2$, nourris ad libitum d'un régime commercial et pesés à 0,2 et 4 semaines d'âge.

Cet essai est poursuivi pendant 8 périodes de 28 jours à partir de la $25^{\mathbf{e}}$ semaine d'âge. 
TABLEAU I

Composition des régimes de l'essai I (\%)

Composition of diets used in trial $I$ (per cent)

\begin{tabular}{|c|c|c|c|c|c|c|}
\hline $\begin{array}{l}\text { Régime de base } \\
\text { Basal diet }\end{array}$ & \multicolumn{2}{|c|}{$\mathrm{I}$} & \multicolumn{2}{|c|}{2} & \multicolumn{2}{|c|}{3} \\
\hline Avoine $($ Oats $)$. . . . . . . . & \multicolumn{2}{|c|}{16,70} & \multicolumn{2}{|c|}{8,35} & \multicolumn{2}{|c|}{ o } \\
\hline Blé (Wheat). . . . . . . . . . . & \multicolumn{2}{|c|}{20,00} & \multicolumn{2}{|c|}{10,00} & \multicolumn{2}{|c|}{ o } \\
\hline Mais (Maize) & \multicolumn{2}{|c|}{32,00} & \multicolumn{2}{|c|}{47,00} & \multicolumn{2}{|c|}{62,00} \\
\hline Tourteau Soja 5o (Soyabean meal 5o). & \multicolumn{2}{|c|}{5,00} & \multicolumn{2}{|c|}{8,10} & \multicolumn{2}{|c|}{ II, 20} \\
\hline $\begin{array}{c}\text { Tourteau Tournesol } 42 \text { (Sunflower meal } \\
42)\end{array}$ & \multicolumn{2}{|c|}{ I0,00 } & \multicolumn{2}{|c|}{$5.5^{\circ}$} & \multicolumn{2}{|c|}{ I,oo } \\
\hline Farine de Poisson 70 (Fish meal 7o) & \multicolumn{2}{|c|}{$I, \infty O$} & \multicolumn{2}{|c|}{$\mathrm{I}, \mathrm{OO}$} & \multicolumn{2}{|c|}{$1, \infty$} \\
\hline Farine de Viande $5^{\circ}$ (Meat meal 50$)$ & \multicolumn{2}{|c|}{5,00} & \multicolumn{2}{|c|}{3,00} & \multicolumn{2}{|c|}{1,00} \\
\hline Gluten de mais 62 (Maize gluten 62). & \multicolumn{2}{|c|}{ o } & \multicolumn{2}{|c|}{3.50} & \multicolumn{2}{|c|}{7,00} \\
\hline Suif (Tallow) . . . . . . . . . . . & \multicolumn{2}{|c|}{$\mathrm{I}, \mathrm{OO}$} & \multicolumn{2}{|c|}{$3,5^{\circ}$} & \multicolumn{2}{|c|}{6,00} \\
\hline $\mathrm{NaCl}$ iodé $(\mathrm{NaCl}$ iodized $) .. . .$. & \multicolumn{2}{|c|}{$0,5^{\circ}$} & \multicolumn{2}{|c|}{0,50} & \multicolumn{2}{|c|}{0,50} \\
\hline Calcaire broyé (Ground limestone) . . & & & & & & \\
\hline $\begin{array}{c}\text { Oligoéléments minéraux } \\
\text { mineral premix) }\end{array}$ & & & & & & \\
\hline $\begin{array}{c}\text { Phosphate bicalcique (Dicalcium phos- } \\
\text { phate) }\end{array}$ & c & & & & & \\
\hline $\begin{array}{l}\text { Complément vitaminique }(* *) \text { (Vitamin } \\
\text { premix) }\end{array}$ & & & & & & \\
\hline Cellulose (Pure cellulose) . . . . . . & & & & & & \\
\hline $\begin{array}{l}\text { Régime expérimental } \\
\text { Experimental diet }\end{array}$ & I & 2 & 3 & I $\mathrm{M}$ & $2 \mathrm{M}$ & $3 \mathrm{M}$ \\
\hline DL méthionine . . . . . . . . . . & 一 & 一 & $\longrightarrow$ & 0,15 & 0, I 5 & 0,15 \\
\hline 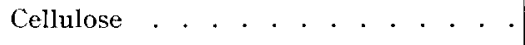 & O, I 5 & 0,15 & O, I 5 & - & - & - \\
\hline Énergie métabolisable (M.E.) kcal $/ \mathrm{kg}$. & 2675 & 2885 & 3095 & 2675 & 2885 & 3095 \\
\hline $\mathrm{N} \times 6,25 \%$ & 17,0 & $\mathrm{I} 7, \mathrm{I}$ & $I_{7}, \mathrm{I}$ & 17,2 & I 7,3 & 17,3 \\
\hline Méthionine $\%$. . . . . . . . . . . . . . & 0,29 & $0,3 \mathrm{I}$ & 0,32 & 0,44 & 0,46 & 0,47 \\
\hline Méthionine + cystine $\%$. & 0,64 & 0,64 & 0,65 & 0,79 & 0,79 & 0,80 \\
\hline Lysine \% . . . . . . . . . . . . . . . . . . & 0,73 & 0,70 & 0,67 & 0,73 & 0,70 & 0,67 \\
\hline $\begin{array}{l}\text { Calcium } \% \text { - } . ~ \\
\text { Phosphore disponible } \% \text { Availablephos- }\end{array}$ & 3,08 & 3,06 & 3,04 & 3.08 & 3,06 & 3,04 \\
\hline phorus). . . . . . . . . . . . . & 0,40 & 0,37 & 0,33 & $0,4^{\circ}$ & 0,37 & 0,33 \\
\hline
\end{tabular}

(*) Apportant pour xoo $\mathrm{kg}$ (en $\mathrm{g})$ : cuivre $=0,2 \mathbf{I}$; fer $=2, \mathrm{r}$; manganèse $=6,4$; zinc $=5,8$; cobalt $=0,021$; iode $=0,08$. Providing per $100 \mathrm{~kg}$ of diet $:$ copper $=0.2 I \mathrm{~g}$; iron $=2.1 \mathrm{~g}$; manganese $=6.4 \mathrm{~g}$; $\operatorname{sinc}=5.8 \mathrm{~g} ;$ cobalt $=0.02 \mathrm{I} \mathrm{g} ;$ iodine $=0.08 \mathrm{~g}$.

(**) Apportant pour roo $\mathrm{kg}$ : vitamine $\mathrm{A}=800$ o00 U.I.; vitamine $\mathrm{D}_{3}=$ I 00 o0o U.I.; vitamine $\mathrm{E}$ $=3 \mathrm{~g}$; riboflavine $=0,5$; nicotinamide $=\mathrm{I} \mathrm{g}$; vitamine $\mathrm{B}_{12}=0,2 \mathrm{mg}$; choline $=\mathrm{I} 2,5 \mathrm{~g} ; \mathrm{B} . \mathrm{H} . \mathrm{T}$. $=\mathrm{I} 5 \mathrm{~g}$; avoine q.s.p. I ooog. Providing per $100 \mathrm{~kg}$ of diet : vitamin $A=800000 \mathrm{I} . U$.; vitamin $D_{3}=I 00$ ooo I.U.; $\alpha$ tocopheryl acetate $=3 \mathrm{~g} ;$ riboflavine $=0.5 \mathrm{~g} ;$ niacine $=I \mathrm{~g} ;$ vitamin $B_{12}=0.2 \mathrm{mg} ;$ choline $=12.5 \mathrm{~g} ;$ B.H.T. = $I 5 \mathrm{~g} ;$ Oats to $\mathrm{I}$ ooo g.

$$
\text { Essai no } 2(\text { (1972-1973) }
$$

Cet essai est destiné à la poursuite de la détermination du besoin énergétique de la Vedette I.N.R.A. JV I5. Il permet en outre de rechercher l'effet d'une addition de L lysine et d'une supplémentation en DL méthionine inférieure à celle de l'essai $n^{0}$ I. 
Il porte sur 576 poules nourries durant leur croissance à l'aide d'un aliment unique suivant des normes très voisines de celles, déjà mentionnées, fournies par le sélectionneur. A 18 semaines, 576 poules réparties en 4 classes de poids sont mises en batterie selon un dispositif en blocs casualisés. Chacun des 48 blocs comporte 12 poulettes d'une même classe de poids qui reçoivent chacune un aliment différent. Cet essai est poursuivi pendant 6 périodes à partir de la $28^{\mathrm{e}}$ semaine d'âge.

Trois aliments de base dont la composition figure dans le tableau 2 servent à constituer les $\mathrm{I} 2$ régimes expérimentaux. Les 3 aliments de base qui ont la même teneur en protéine, lysine, méthionine et acides aminés soufrés mais des teneurs différentes en énergie, permettent d'alimenter les animaux à 3 niveaux énergé-

\section{TABLEAU 2}

Composition des régimes de base de l'essai 2 (\%)

Composition of basal diets used in trial 2 (per cent)

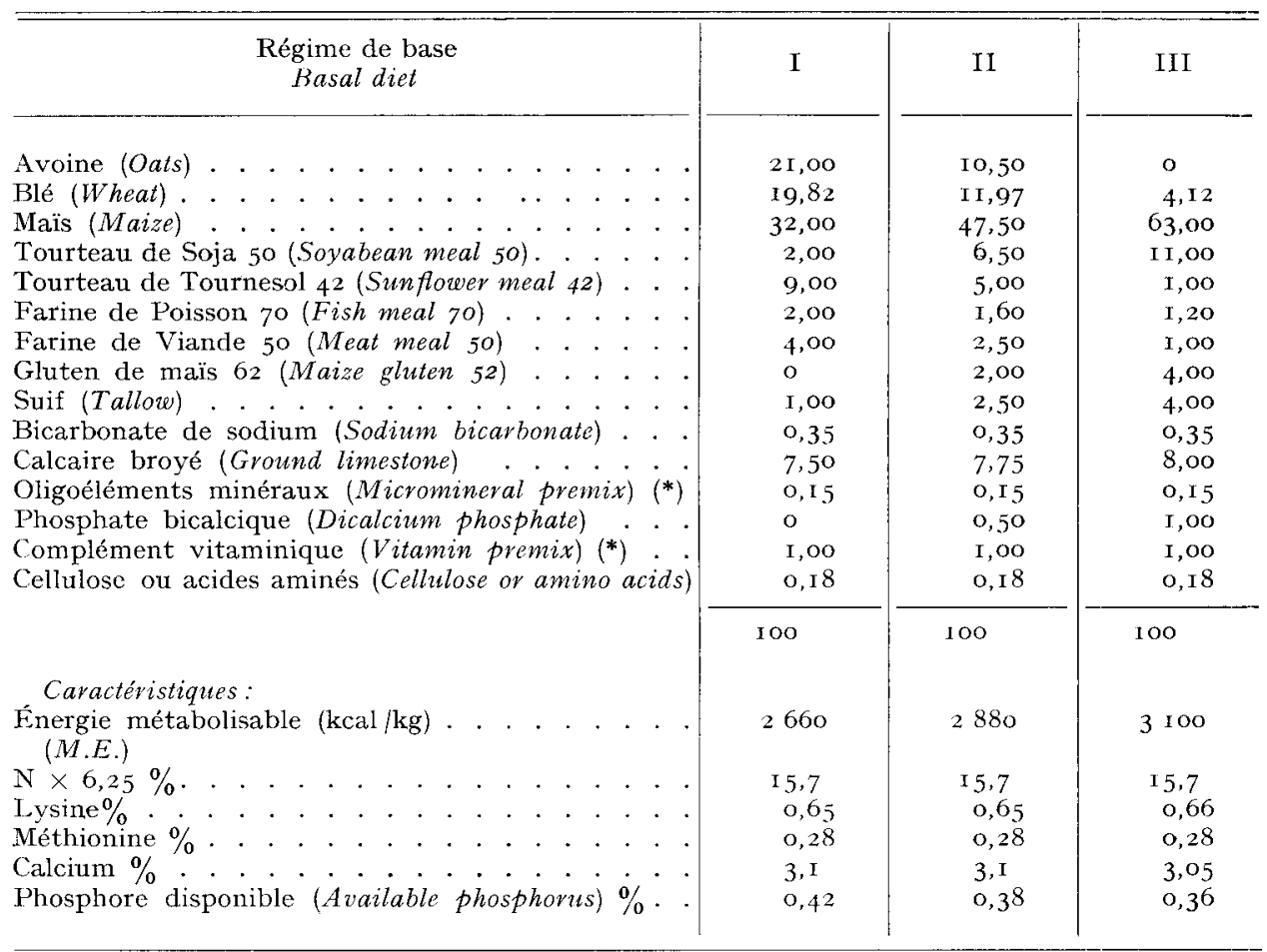

(*) Mêmes apports que dans l'essai I. Providing the same amounts as in trial I (Table I).

tiques: 300,320 et $340 \mathrm{kcal} / \mathrm{jour}$. Les 12 régimes sont constitués par les 3 aliments de base non supplémentés en acides aminés ou supplémentés par o,08 p. Ioo de L lysine chlorhydrate, ou par o, I p. Ioo de DL méthionine ou par o,o8 p. Ioo de L lysine chlorhydrate et o,r p. Ioo de DL méthionine (c'est-à-dire un supplément de L lysine et de DL méthionine égal à 8 et I 6 p. Ioo respectivement des recommandations de l'A.E.C. déjà citées). 


\section{Essais no 3 et 3 bis (1973-I974)}

Cette expérience est subdivisée en deux essais de même durée, décalés de 4 mois dans le temps, mais effectués dans le même bâtiment sur des batteries semblables.

Le but essentiel de ces deux essais est de relier la quantité de méthionine consommée au poids corporel moyen, au gain de poids et à la production d'cufs exprimée en $\mathrm{g} / \mathrm{jour}$.

Ces essais commencent à la $26^{\mathrm{e}}$ semaine et comportent 5 périodes de 28 jours. I.es poules sont pesées à la fin de chacune de ces périodes.

L'essai no 3 porte sur 288 poulettes JV I 5 élevées au sol et rationnées selon les normes du sélectionneur. Elles sont mises en batteries à I'âge de 18 semaines. Contrairement aux essais précédents, elles sont placées au hasard dans la batterie sans répartition en classe de poids. En revanche, ces poules sont pesées à la fin de chacune des 5 périodes de 28 jours. Les poules sont âgées de 26 semaines au début de la première période.

\section{TABLEAU 3}

Composition des régimes des essais 3 et 3 bis (\%)

Composition of diets used in trials 3 and 3 bis (per cont)

Régime de hase (carencé en méthionine) - Basal diet (methionine deficient)

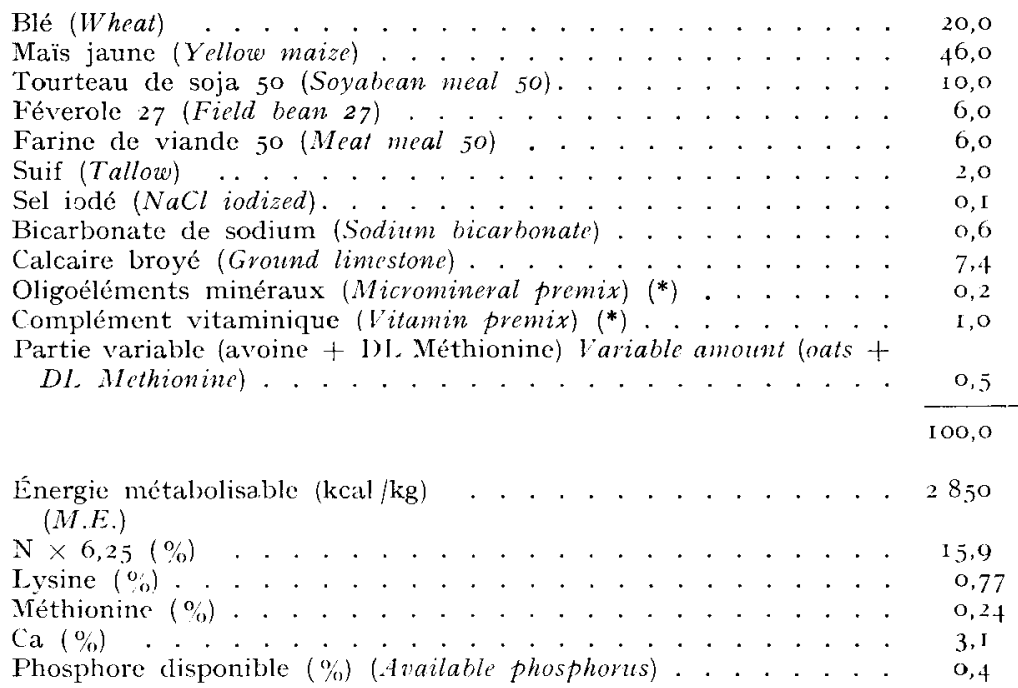

Supplémentation cu méthionine. DL methionine supply

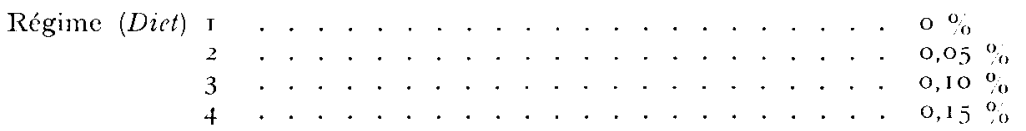


Les 4 régimes isoénergétiques distribués (tabl. 3) ne diffèrent que par la dose de DL méthionine qui y est incorporée, de sorte que leur teneur en méthionine totale passe de $0,24 \mathrm{p}$. Ioo (régime I carencé) à $0,29,0,34$ et $0,39 \mathrm{p}$. Ioo dans les régimes 2,3 et 4 respectivement. La mise en expérience se fait dans les mêmes conditions que dans l'essai $n^{\circ} 3$. Toutefois, on répartit les poulettes naines et normales sur des étages différents de la batterie.

Dans I'essai $n^{\circ} 3$ bis les I44 poulettes normales (Dw-) et les I44 poulettes naines ( $d w-)$ sont également rationnés durant leur phase d'élevage, mais la dose distribuée aux poulettes naines est ajustée pour tenir compte de la réduction progressive du poids corporel de ces animaux au cours de la croissance. Seuls les régimes $I, 2$ et 4 sont distribués au cours de cet essai, le régime à 0,34 p. Ioo de méthionine étant exclu. Cet essai débute au même âge que l'essai no 3 .

Les méthodes utilisées pour l'étude statistique des résultats sont l'analyse de la variance sur la consommation d'aliment, l'intensité de ponte, le poids moyen de l'œuf et le poids d'œuf pondu par jour, ainsi que (essais no 3 et 3 bis) sur le gain de poids des poules. Dans tous les cas l'analyse de variance est faite sur des dispositifs factoriels. Un nombre inégal de données apparaissant dans les divers lots par suite de la mortalité, on utilise la méthode des "fitting constants » (SNEDEcor et Cochran, I97I) pour évaluer l'effet des facteurs étudiés.

Du fait de la faiblesse relative de nos effectifs les données concernant la mortalité ne sont pas analysées.

\section{Résultats}

\section{Essai $n^{0} \quad I$}

Les principaux résultats de cet essai sont consignés dans les tableaux 4 et $\mathbf{5}$. Il faut noter d'abord l'existence d'une mortalité importante due essentiellement à la maladie de Marek (I).

Par rapport au rationnement recommandé, ce rationnement sévère réduit le poids des poules (de I $3 \%$ et I $5 \%$ aux âges de $\mathrm{I} 7$ et 20 semaines respectivement). Toutefois, à l'intérieur de chaque lot l'hétérogénéité qui subsiste permet la constitution de classes de poids extrêmes différant de 0,24 et $0,23 \mathrm{~kg}$ à $\mathrm{I} 7$ et 20 semaines d'àge respectivement. Ces différences s'atténuent avec le temps puisque le gain de poids journalier est d'autant plus important que le poids initial des poulettes était plus faible, quelle que soit l'origine de la variabilité du poids. Il s'avère aussi que la mortalité est beaucoup plus importante chez les sujets légers (2).

Le poids moyen de l'œuf ne diffère pas significativement d'un lot à l'autre. L'intensité de ponte n'est pas modifiée par le rationnement, mais, en revanche, elle varie notablement selon la classe de poids : les poules lourdes pondent 20 p. I 00 plus d'œufs que les légères. La consommation ne diffère que faiblement d'un groupe à l'autre (du fait du rationnement imposé pendant la ponte). L'efficacité alimentaire est meilleure dans les lots rationnés sévèrement $(+5,5 \%)$; dans les classes de poids supérieures elle tend, elle aussi, à être plus élevée $(+2,5 \%)$ malgré le handicap de ces animaux dû à leur besoin d'entretien accru.

(I) Une vaccination contre la maladie de Marek avait été pratiquée (novembre I97o); mais, pour une raison inconnue, elle s'est avérée inefficace.

(2) Nous n'en tirons cependant aucune relation causale, l'infection, bien entendu accidentelle, ayant pu apparaître à un moment différent dans les diverses cellules d'élevage. 


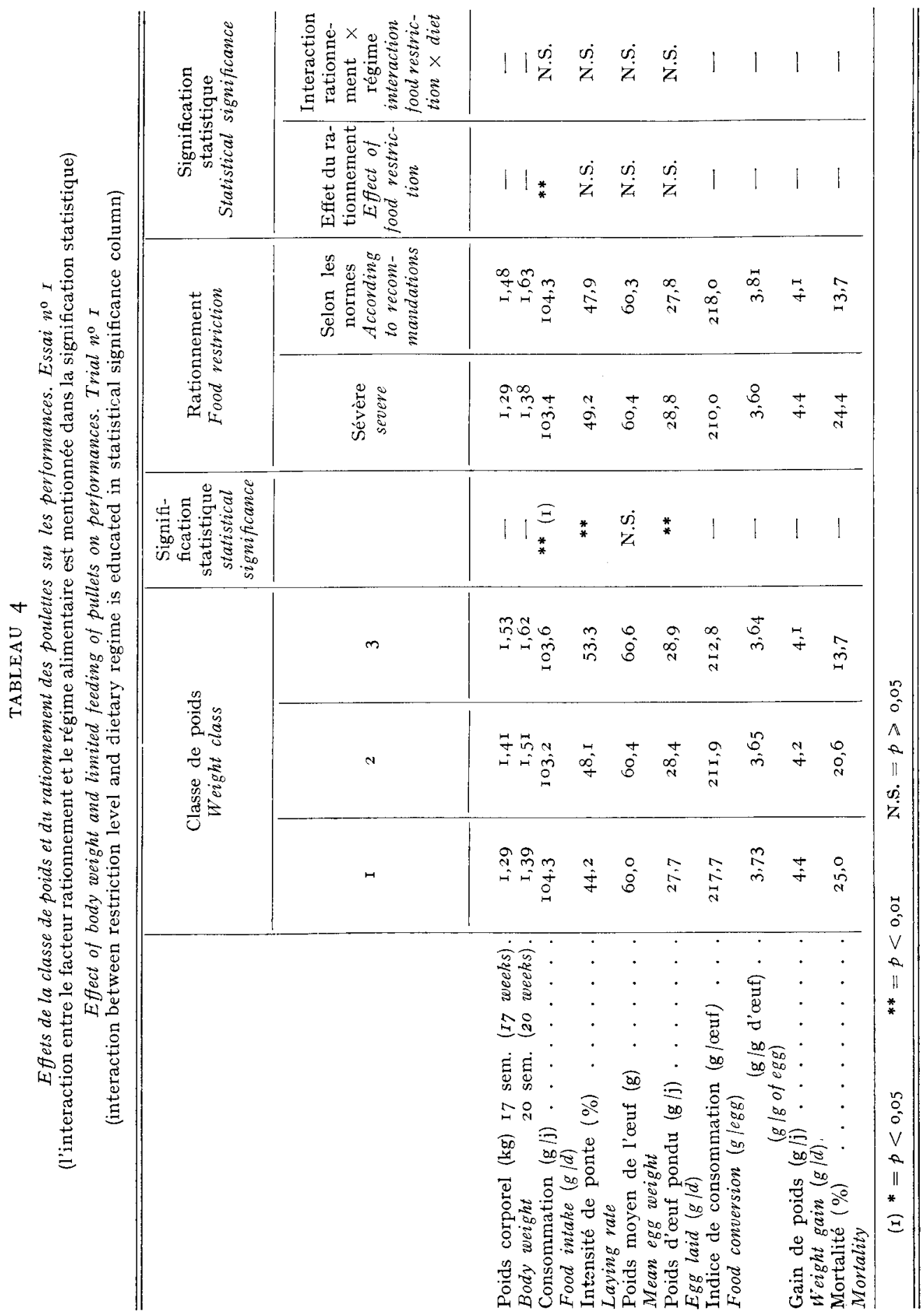




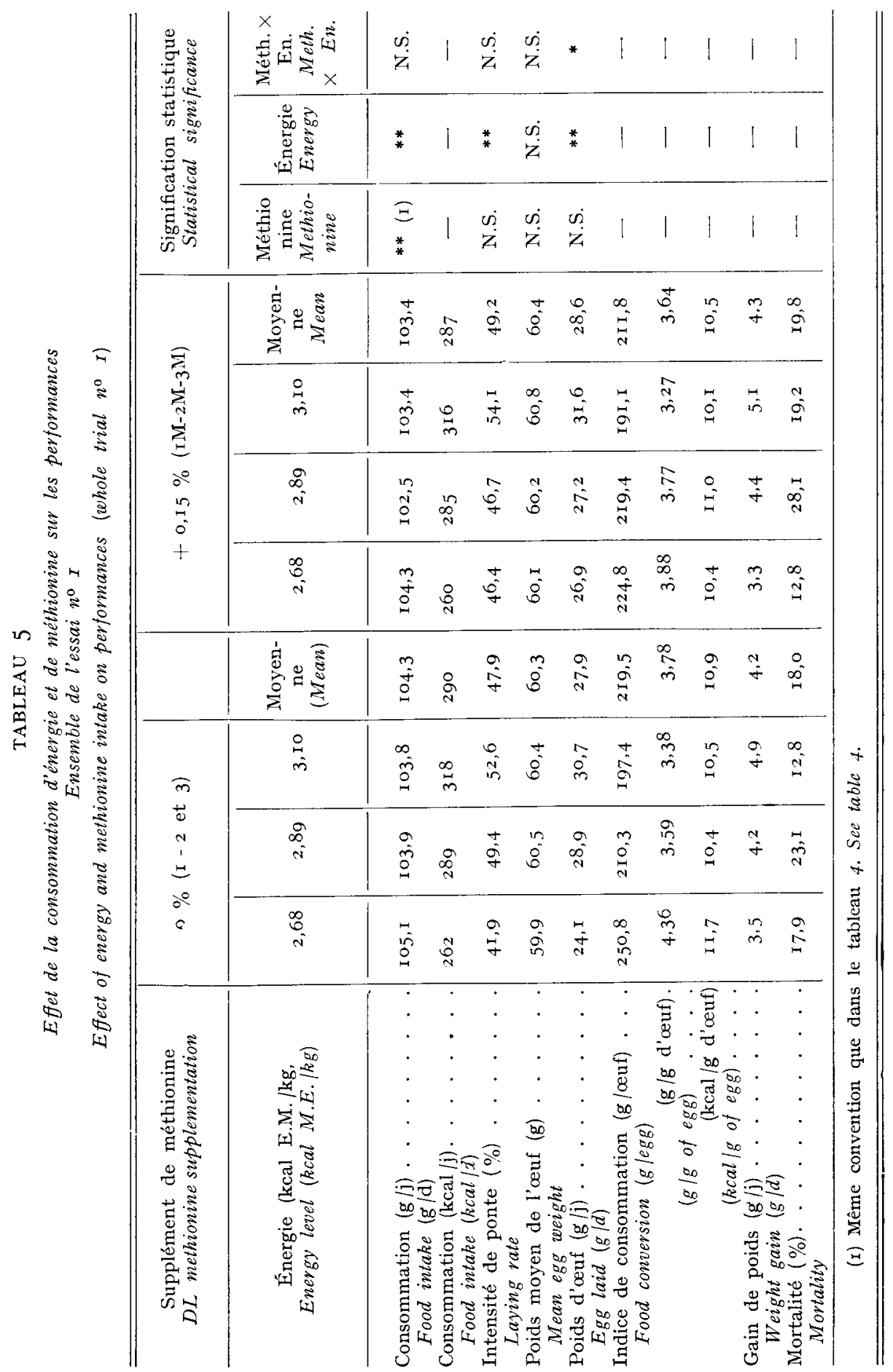




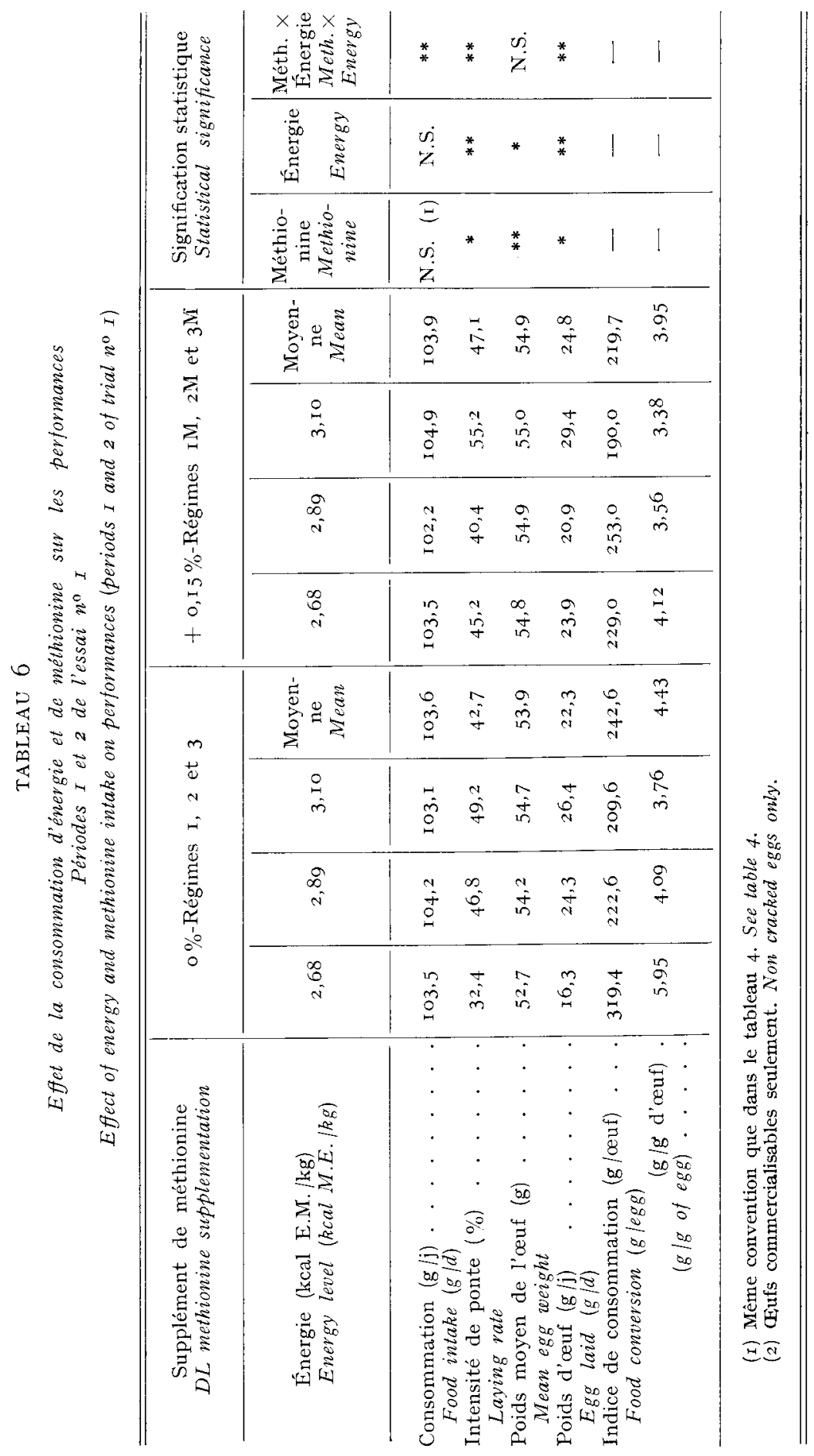


BESOINS DE LA POULE REPRODUCTRICE VEDETTE (dw)

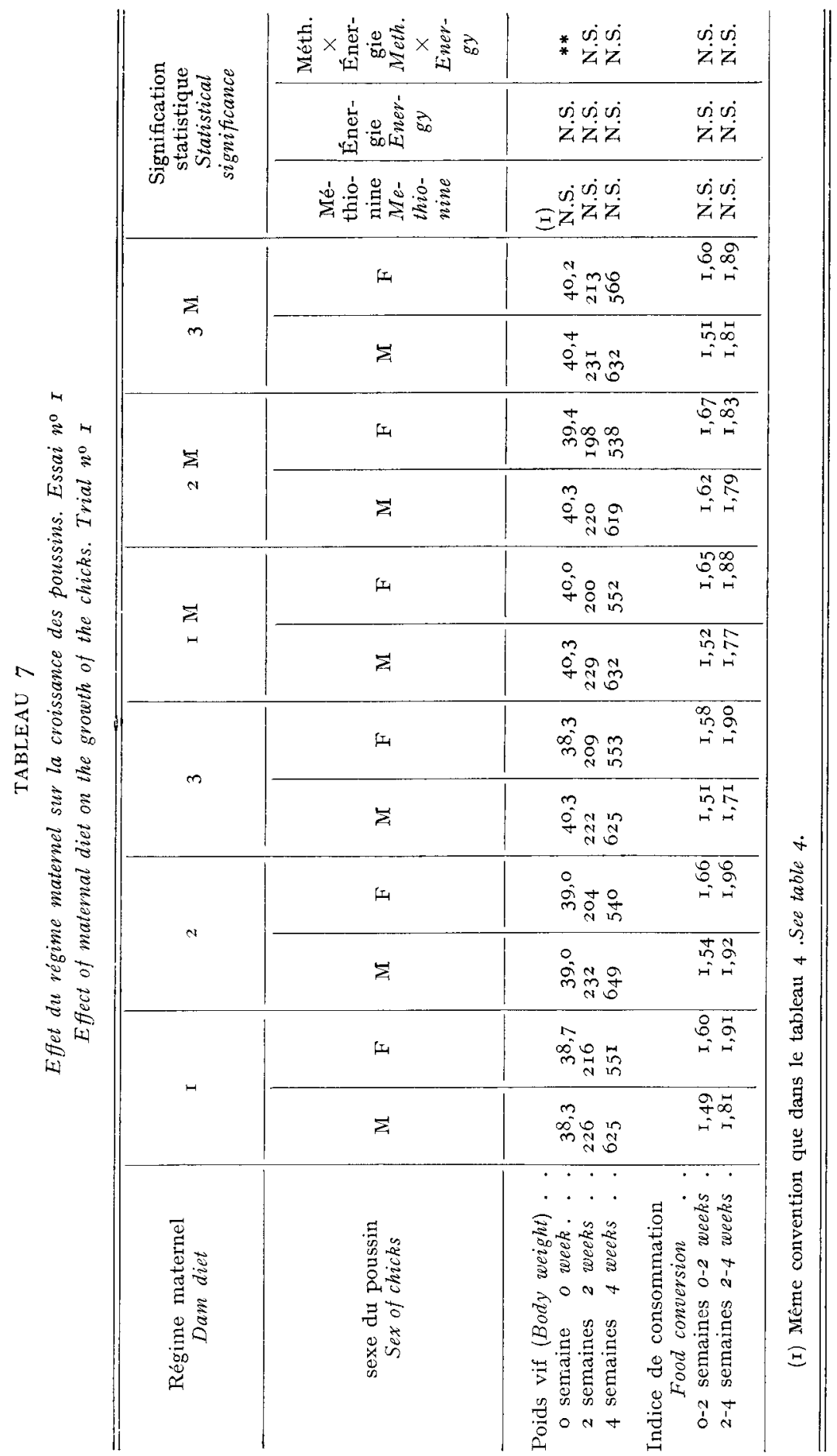


Dans aucun cas on ne note d'interaction entre le rationnement durant la période d'élevage et le régime alimentaire éprouvé. Parmi les facteurs alimentaires étudiés, l'énergie exerce l'effet le plus net : avec les régimes extrêmes l'ingéré passe de 260 à $318 \mathrm{kcal}$ E.M. /jour. Il en résulte une nette amélioration du gain de poids corporel et de l'intensité de ponte. La consommation, en g d'aliment, bien qu'influencée de façon significative par le régime, varie dans une très faible marge à cause du rationnement imposé tandis que le poids de l'œuf n'est pas influencé de façon significative par le traitement. L'indice de consommation apparaît d'autant meilleur que la ration énergétique est plus copieuse. Toutefois, l'efficacité énergétique (kcal par g d'œuf) apparaît très peu variable.

La méthionine n'exerce à première vue qu'un effet très limité sur les critères étudiés : elle tend, certes, à augmenter légèrement le nombre et la masse des œufs et à diminuer la consommation; mais seul ce dernier effet (d'importance limitée par suite du rationnement) est significatif. L'addition de méthionine a, en fait, une action très marquée au début de la ponte (tabl. 6) : durant les 8 premières semaines elle augmente à la fois l'intensité de ponte et le poids moyen de l'œuf. Cet effet est plus accentué dans les lots recevant une faible ration énergétique. La production d'œufs (en $\mathrm{g} / \mathrm{j}$ ) est accrue par la supplémentation de $43 \mathrm{p}$. Ioo dans les lots les plus carencés en énergie et de I I p. Ioo seulement dans les non carencés (interaction hautement significative, $\mathrm{p}<\mathrm{o}, \mathrm{OI}$ ) et réduite de $\mathrm{I} 4 \mathrm{p}$. IoO dans les lots recevant un régime à $2,89 \mathrm{Mcal} / \mathrm{kg}$.

Les principaux résultats de l'essai de croissance de la descendance sont rassemblés dans le tableau 7. L'effet du régime maternel sur le poids du poussin à la naissance est extrêmement net. Dans les lots nourris des régimes non supplémentés en méthionine, les poules les plus carencées en énergie engendrent des poussins plus légers, tandis que dans les lots recevant l'aliment supplémenté le poids du poussin est à peu près indépendant de la ration énergétique (interaction significative $p<0$, I). Il faut rappeler que les oufs utilisés dans cet essai ont été pondus au $5^{\mathrm{e}}$ mois, c'est-à-dire à un moment où l'on n'observe plus d'effet notable de la méthionine sur le poids de l'œuf. Toutefois, on n'observe plus d'effet significatif du régime maternel à partir de l'âge de 2 semaines sur la croissance ou l'efficacité alimentaire des mâles ou des femelles.

\section{Essai $n^{\circ} 2$}

Les principaux résultats de l'essai $n^{\circ} 2$ sont rassemblés dans les tableaux 8 , 9 et Io. On observe durant tout l'essai une mortalité assez importante due essentiellement au foie gras hémorragique et un pourcentage non négligeable de poules ne commence à pondre qu'après la $30^{\mathrm{e}}$ semaine; ces anomalies sont indépendantes des régimes alimentaires. Malgré cela les observations suivantes peuvent être faites :

La classe de poids exerce un effet significatif sur certaines performances (tabl. 8) : les poules les plus lourdes ont tendance à pondre moins tandis que le poids moyen de leur œuf est nettement plus élevé $(p<0,05)$. Elles ont également tendance à consommer davantage.

La supplémentation en lysine n'exerce aucun effet significatif sur les critères enregistrés sur l'ensemble de l'essai. En fait, si on se limite à la $3^{\mathrm{e}}$ période de ponte, c'est-à-dire au moment de la production maximale, la supplémentation en L lysine accroît la production de ro p. IoO $(p<0,0$ I) (tabl. 9$)$.

Les autres facteurs d'ordre nutritionnel apportent d'intéressantes précisions 
TABLEAU 8

Effet de la classe de poids sur les performances. Essai no 2 Effect of body weight class on performances. Trial $n^{0} 2$

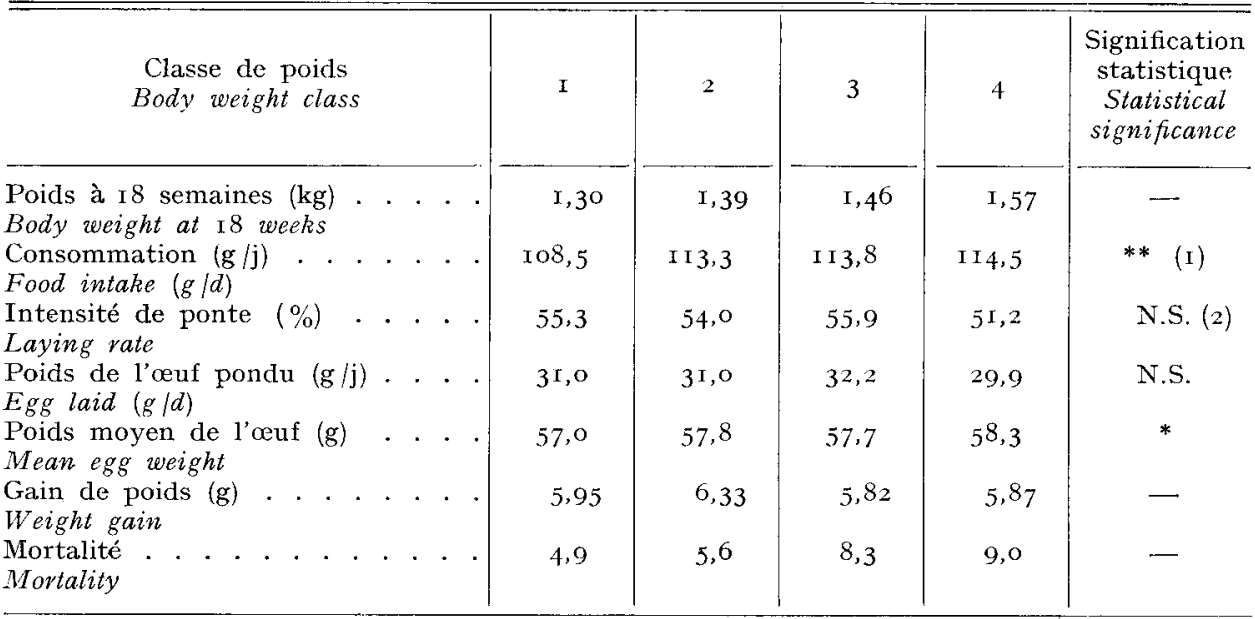

(I) Même convention que dans le tableau 4. See table 4 .

(2) I a différence est cependant significative $(p<0,05)$ si l'on considère les œuf commercialisables (à coquille normale) et non le total des oufs pondus, le pourcentage de casse étant plus élevé chez Ies poules lourdes. However the difference is significant $(\mathrm{p} .<0.05)$ if number of non cracked egg instead of total eggs is taken into account, the percentage of cracked eggs being higher in heavy hens.

TABLEAU 9

Effet de la supplémentation en lysine sur les performances. Essai $n^{\circ} 2$ Effect of lysine supplementation on performances. Trial $n^{\circ} 2$

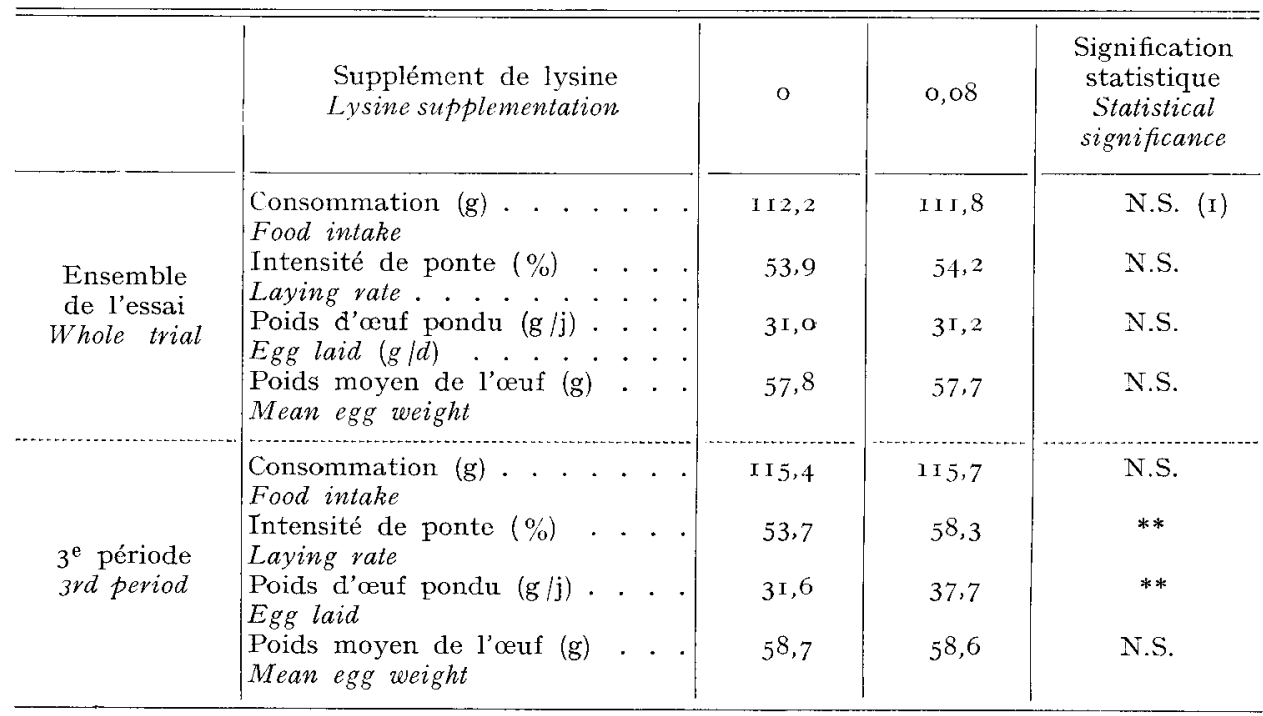

(I) Même convention que dans le tableau 4. See table 4. 


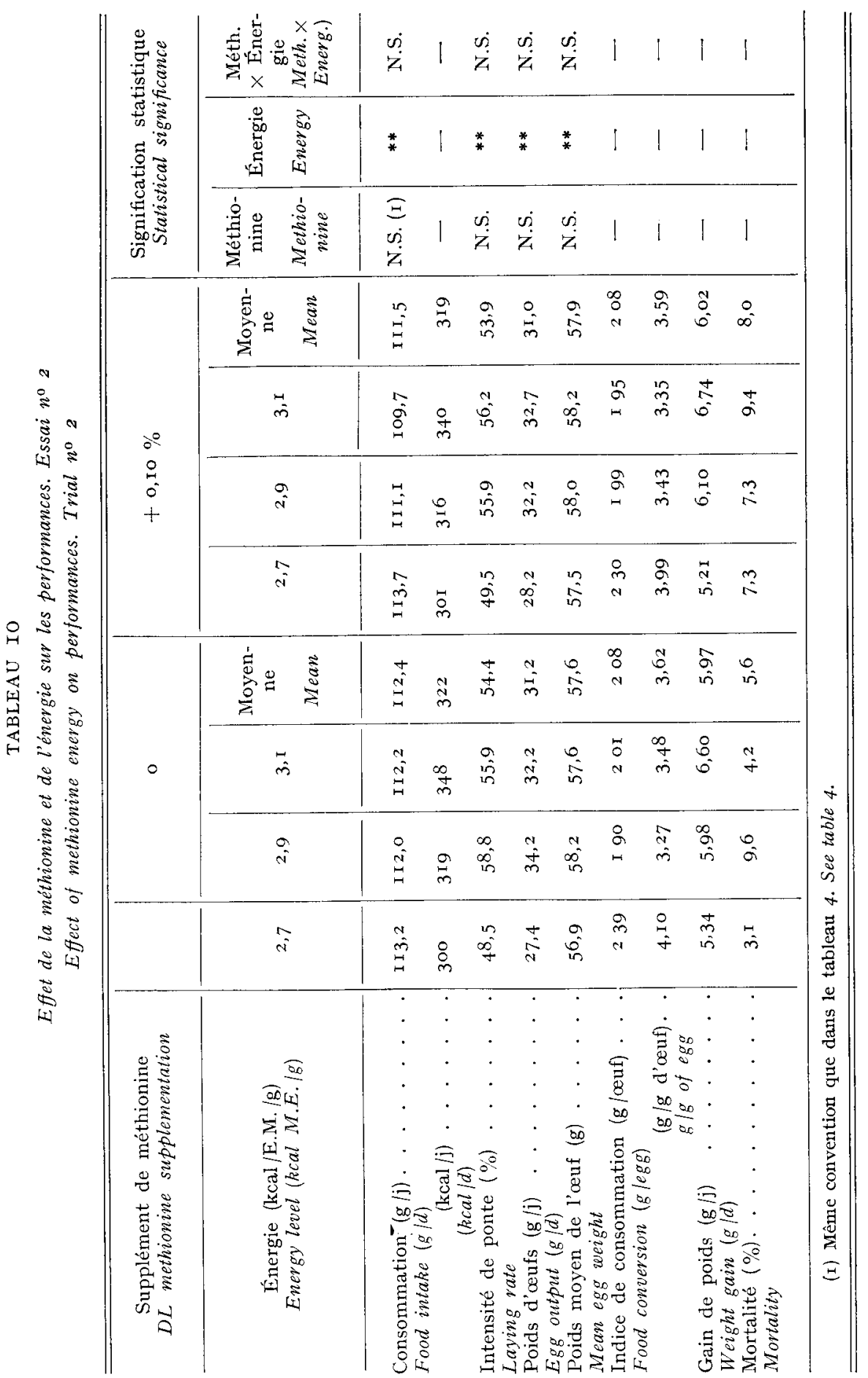


(tabl. Io) : l'intensité de ponte et le poids moyen des œufs sont les plus faibles chez les poules rationnées à $300 \mathrm{kcal} / \mathrm{j}$. Au-delà de $320 \mathrm{kcal} / \mathrm{j}$, les performances des poules plafonnent.

La supplémentation à l'aide de o, Io p. Ioo de méthionine n'exerce, à première vue, aucune influence sur les caractères contrôlés; on observe, cependant, comme dans l'essai précédent, une augmentation de I 8 p. Ioo de la masse d'œufs pondus durant les 8 premiers mois dans les lots nourris de l'aliment supplémenté de 5 p. roo. Toutefois cette amélioration n'atteint pas le seuil de signification $(F=3,05-$ I-5494 DL).

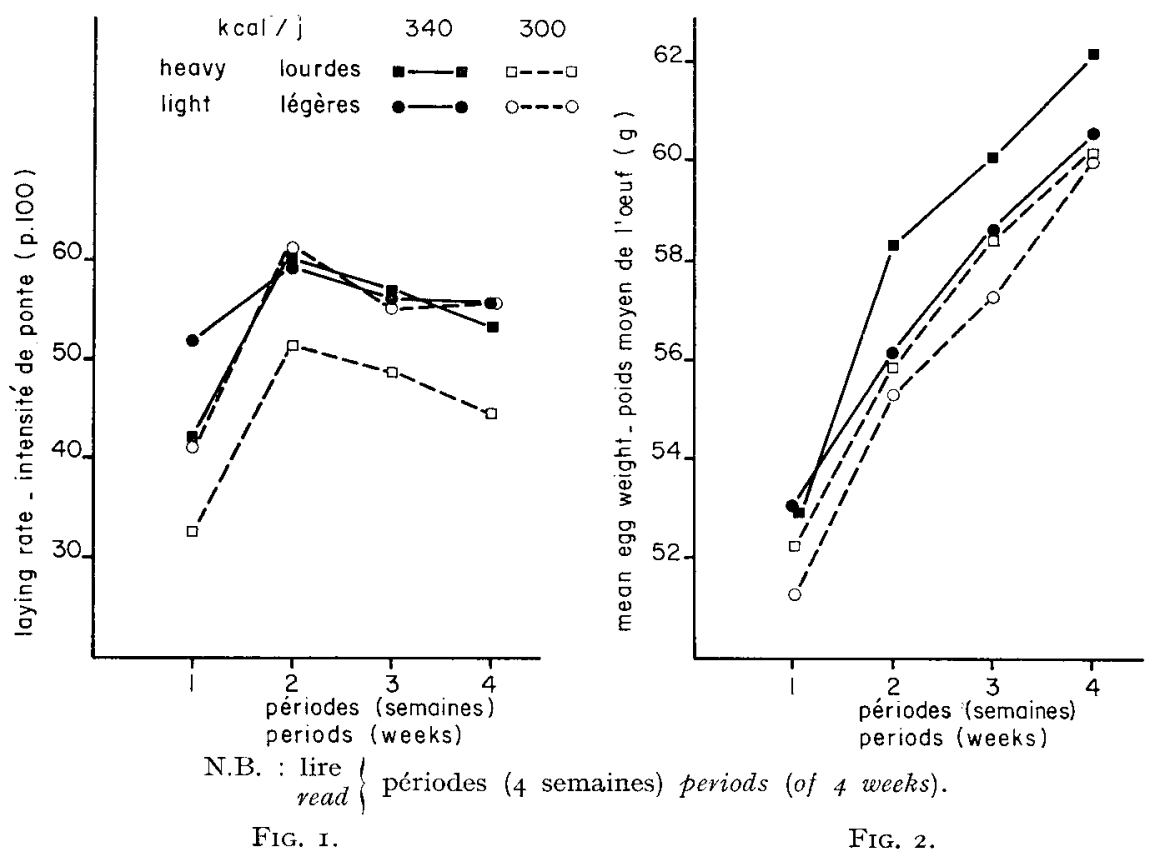

FIG. I. - Effet du vationnement en énergie sur l'intensité de ponte chez les poules lonvdes et légères (Essai 2).

Effect of energy restriction on laying rate in heavy and light birds (trial 2).

FIG. 2. - Effet du rationnement en énergie sur le poids moyen de l'aut chez les poules lourdes et légères (Essai 2).

Effect of energy restriction on mean egg weight in heavy and light birds (trial 2 )

On observe aussi une interaction (de probabilité voisine de 0,05 ) entre classe de poids et ration énergétique. Pour le rationnement de $300 \mathrm{kcal} / \mathrm{j}$ chez les poules lourdes, le poids et surtout le nombre d'œufs sont nettement réduits alors que chez les plus légères, seul le poids de l'œuf diminue légèrement (fig. I et 2).

\section{Essai $n^{\circ} 3$}

Les principaux résultats de l'essai no 3 sont rassemblés dans le tableau II. Bien que l'apport de méthionine par les 4 régimes passe de 80 à I 30 p. Ioo de l'apport recommandé, il n'existe aucune différence entre les lots en ce qui concerne la consommation et le poids des poules. Le poids moyen de l'œuf est certes influencé 
TABLEAU I I

Effet de la teneur en méthionine du régime sur les performances. Fssai $n^{\circ} 3$ Effect of methionine content on performances. Trial $n^{\circ} 3$

\begin{tabular}{|c|c|c|c|c|c|c|}
\hline $\begin{array}{l}\text { Teneur en méthionin } \\
\text { Methionine content }\end{array}$ & $(\%)$ & 0,24 & 0,29 & 0,34 & 0,39 & $\begin{array}{l}\text { Signification } \\
\text { statistique } \\
\text { Statistical } \\
\text { significance }\end{array}$ \\
\hline Poids initial (kg) . & . . . & $2, \mathrm{OI}$ & 1,98 & 2,05 & 2,03 & N.S. (I) \\
\hline $\begin{array}{l}\text { Intial werght } \\
\text { Consommation }(\mathrm{g} / \mathrm{j}) \text {. . . } \\
\text { Food intake }\end{array}$ & $\cdot \cdot \cdot$ & 108,5 & 108,8 & 107,6 & I 08,9 & N.S. \\
\hline $\begin{array}{l}\text { Consommation de méthionine } \\
\text { Methionine intake }(m g / d)\end{array}$ & $(\mathrm{mg} / \mathrm{j})$ & 260 & $3+5$ & 366 & 425 & - \\
\hline $\begin{array}{l}\text { Intensité de ponte }(\%) \\
\text { Laying rate }\end{array}$ & $\cdot \cdot \cdot \cdot$ & $5^{8,2}$ & $.58,7$ & $5^{6,4}$ & 55,5 & N.S. \\
\hline $\begin{array}{l}\text { Poids moyen de l'ouf (g) } \\
\text { Mean egg weight }\end{array}$ & $\cdot \cdot \cdot$ & $5^{6,5}$ & $5^{6,8}$ & 57,8 & $5^{8,1}$ & $* *$ \\
\hline $\begin{array}{l}\text { Poids d'ouf pondu }(\mathrm{g} / \mathrm{j}) \\
\text { Egg laid }(g / d) \\
\text { Indice de consommation } \\
\text { Food conversion }\end{array}$ & $\cdot \cdot \cdot$ & 32,6 & 32,9 & 32,2 & 31,9 & N.S. \\
\hline $\begin{array}{l}(\mathrm{g} / \text { ouf }) \\
(g / \log )\end{array}$ & . . & I 86,4 & $\mathrm{I} 85.3$ & 190,8 & 196,2 & 一 \\
\hline $\begin{array}{l}(\mathrm{g} / \mathrm{g} \text { d'œuf }) \\
(g / g \text { of } e g g)\end{array}$ & $\cdot \cdot \cdot$ & 3,33 & $3,3 \mathrm{I}$ & 3,34 & 3.4 I & - \\
\hline Gain de poids $(\mathrm{g} / \mathrm{j})(2)$. & $\cdot$. & 2,5 & 2,5 & 2,5 & 2,7 & N.S. \\
\hline 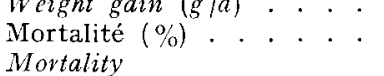 & $\cdot \cdot \cdot \cdot$ & 5,5 & 4,2 & 0 & 2,8 & $\longrightarrow$ \\
\hline
\end{tabular}

(r) Même convention que dans le tabicau 4. Sce table 4 .

(2) Mesuré sur les 5 mois de période expérimenta le seulement et non depuis la mise en cage comme dans les essais $\mathrm{x}$ et 2 . Measured during the last 5 months only and not from the time whon the birds were alloted in cages as in trials $I$ and 2 .

de manière extrêmement nette par la supplémentation en méthionine, mais l'augmentation du poids moyen est compensée par une diminution (non significative) de l'intensité de ponte. Il faut noter aussi que l'effet de la méthionine ajoutée est le même à chaque période. Par ailleurs aucun autre effet du traitement - si bref et fugitif soit-il — n'apparaît à l'une quelconque des périodes étudiées.

\section{Essai $n^{0} 3$ bis}

Cet essai révèle (tabl. I2), bien entendu, de grandes différences entı les génotypes. La première concerne l'âge d'entrée en ponte qui est plus précoce, malgré un poids corporel inférieur de 38 p. Ioo, chez les poules naines (différence de 9 jours pour l'âge à 25 p. Ioo de ponte, $p<0,0$ ). Les poules naines comparées à leurs sœurs normales pondent avec une intensité réduite et leurs œufs sont nettement plus petits, la différence $(7 \mathrm{~g})$ restant constante au cours des 5 périodes de l'essai. Toutefois leur consommation est inférieure de 32 p. Ioo si bien que l'efficacité alimentaire s'en trouve améliorée: la quantité d'aliment consommé, par œuf 


\begin{tabular}{|c|c|c|c|c|c|c|c|c|c|c|c|c|c|}
\hline \multirow{12}{*}{ 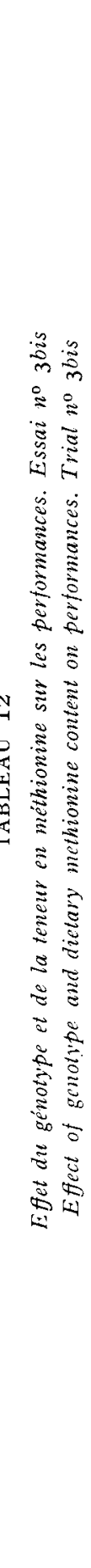 } & \multirow{3}{*}{ 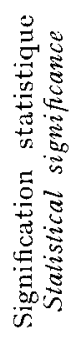 } & 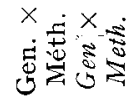 & 1 & $\begin{array}{l}\dot{0} \\
\ddot{4}\end{array}$ & & री & 点 & $\dot{\Omega}$ & 1 & 1 & $\stackrel{*}{*}$ & 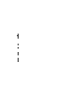 & \\
\hline & & 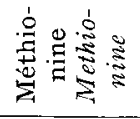 & 1 & 岂 & & $*$ & * & * & 1 & 1 & $\stackrel{*}{*}$ & & \\
\hline & & 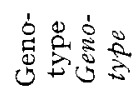 & $\Xi$ & $\stackrel{*}{*}$ & 1 & $\stackrel{*}{*}$ & $\stackrel{*}{*}$ & $\stackrel{*}{*}$ & 1 & 1 & $\stackrel{*}{*}$ & & \\
\hline & & 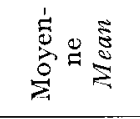 & $\cong$ & $\widehat{D}$ & $\underset{\sim}{\stackrel{0}{0}}$ & $\bar{f}$ & $\ddot{i}$ & $\overrightarrow{\tilde{n}}$ & $\begin{array}{l}0 \\
\tilde{N} \\
\tilde{H}\end{array}$ & $\vec{i}$ & $\vec{i}$ & 0 & \\
\hline & $\stackrel{\Xi}{\Xi}$ & $\begin{array}{c}\text { ले } \\
\vdots \\
0\end{array}$ & $\stackrel{m}{=}$ & $\underset{\infty}{+}$ & $\hat{m}$ & $8_{8}^{1}$ & $\begin{array}{l}m \\
\dot{0}\end{array}$ & $\ddot{\dot{m}}$ & $\stackrel{\substack{1 \\
m}}{m}$ & $\begin{array}{l}+ \\
\infty \\
i\end{array}$ & $\vec{i}$ & 0 & \\
\hline & $\begin{array}{l}\bar{\Xi} \\
\ddot{Z} \\
\bar{Z}\end{array}$ & $\begin{array}{l}\stackrel{0}{7} \\
0\end{array}$ & $\stackrel{\hat{m}}{=}$ & $\begin{array}{l}12 \\
\infty \\
\infty\end{array}$ & in & $\infty$ & $\stackrel{m}{i}$ & $\underset{j}{\stackrel{a}{j}}$ & ì & $\begin{array}{l}m \\
i \\
i\end{array}$ & $\overrightarrow{\mathrm{i}}$ & 0 & \\
\hline & & $\frac{\pi}{3}$ & $\hat{m}$ & $\hat{D}_{\infty}^{2}$ & 仓े & $\hat{\hat{\theta}}$ & $\dot{\alpha}$ & $\stackrel{M}{m}$ & $\begin{array}{c}m \\
\stackrel{n}{m}\end{array}$ & 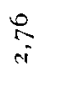 & $\stackrel{\circ}{\mathrm{N}}$ & $\circ$ & \\
\hline & & 吾。 & $\stackrel{\circ}{i}$ & $\begin{array}{l}3 \\
0 \\
0 \\
n\end{array}$ & 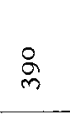 & ô & $\stackrel{4}{i}$ & $\stackrel{\stackrel{\sigma}{+}}{\dot{f}}$ & $\begin{array}{l}0 \\
\dot{8}\end{array}$ & $\begin{array}{l}N \\
\infty \\
\text { ci }\end{array}$ & $\stackrel{\circ}{+}$ & 0 & $\dot{\vec{\Delta}}$ \\
\hline & $\begin{array}{r}13 \\
+3 \\
3 \\
3 \\
3\end{array}$ & $\stackrel{a}{m}$ & $\overrightarrow{z i}$ & $\begin{array}{l}0 \\
9 \\
9 \\
-1\end{array}$ & $\hat{i}$ & $\hat{i}$ & $\stackrel{0}{i}$ & 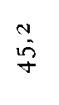 & 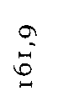 & $\begin{array}{l}10 \\
\infty \\
i\end{array}$ & $\begin{array}{l}0 \\
\dot{f}\end{array}$ & 0 & $\underset{j}{i=\frac{a}{3}}$ \\
\hline & 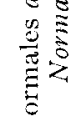 & $\begin{array}{c}\text { a } \\
\text { o } \\
0\end{array}$ & 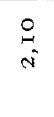 & $\stackrel{\Xi}{N}$ & $\stackrel{8}{\circ}$ & $\stackrel{2}{8}$ & $\stackrel{i}{i}$ & $\begin{array}{l}9 \\
10 \\
y\end{array}$ & $\underset{\substack{m \\
i \\
i}}{m}$ & $\stackrel{i}{\hat{i}}$ & $\stackrel{\circ}{+}$ & 0 & 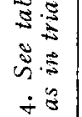 \\
\hline & & $\frac{\pi}{1}$ & $\begin{array}{l}0 \\
0 \\
i\end{array}$ & $\stackrel{I}{I}$ & 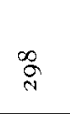 & $\begin{array}{l}0 \\
\mathbb{1}\end{array}$ & $0^{\infty}$ & $\stackrel{0}{\dot{m}}$ & $\begin{array}{c}\stackrel{a}{5} \\
\text { in } \\
\end{array}$ & $\begin{array}{l}\infty \\
\infty \\
i\end{array}$ & $\stackrel{+}{m}$ & 0 & 焉 \\
\hline & 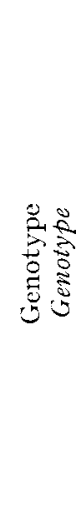 & 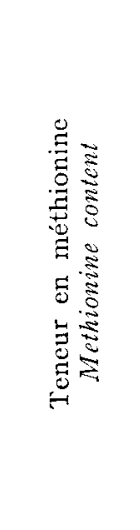 & 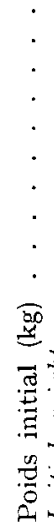 & 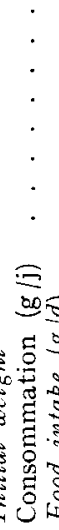 & 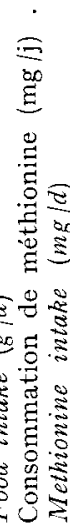 & 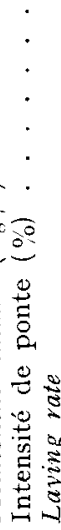 & 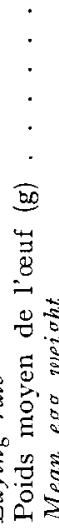 & 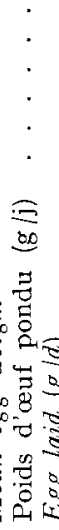 & 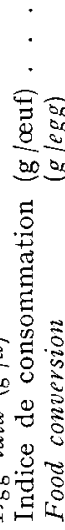 & 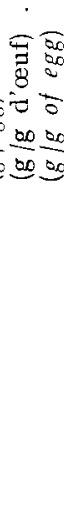 & 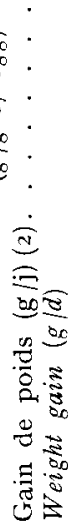 & 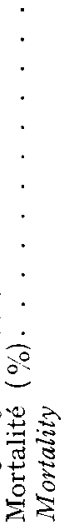 & 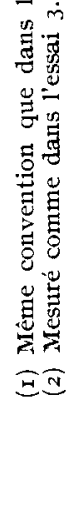 \\
\hline
\end{tabular}


est réduite de I7 p. Ioo et la quantité consommée par g d'œuf l'est de 4 p. Ioo chez les sujets $d w$.

La méthionine exerce également une influence significative sur la production : dans le lot carencé la ponte est moins intense et surtout le poids moyen de l'œuf y est réduit. Par rapport au lot à 0,29 p. Ioo de méthionine cette baisse du poids est de $0,9 \mathrm{~g}$ chez les poules normales et de $\mathrm{I}, 9 \mathrm{che} z$ les poules naines. La masse d'œuf produit est réduite de 5 et de I0,7 p. Ioo dans les génotypes $d w^{+}$et $d w$ respectivement. On observe donc une interaction entre méthionine et génotype : les sujets nains souffrent davantage de la carence en cet acide aminé soufré. Une interaction entre ces mêmes facteurs existe également sur le gain de poids corporel qui est flus faible en cas de carence chez les poules normales et non chez les naines. En d'autres termes l'addition de 0,05 p. Ioo de DL méthionine au régime de base n'améliore que faiblement la production d'œufs et fortement le poids corporel chez les poules normales alors qu'il améliore nettement la ponte chez leurs soeurs naines et pas du tout leur poids corporel.

\section{Discussion}

Les résultats obtenus dans ces trois essais sur la Vedette I.N.R.A. JV I5 appellent quelques remarques : les performances de ponte en batterie sont en effet inférieures à celles que l'on enregistre sur ces mêmes oiseaux élevés au sol (LECLERCQ et BLUM, I972), et même à celles que nous avions obtenues sur des poules JV I5 élevées dans les mêmes batteries, mais appartenant aux premières générations de ce croisement (Leclerco, Guillaume et Blum, I970). La cause de cette régression des performances ne semble pas être l'état sanitaire (au moins dans les essais $n^{\circ} 2$ et 3 ). Il paraît plus vraisemblable d'admettre que la Vedette I.N.R.A., surtout sous sa forme actuelle plus lourde que lors des premières générations, s'adapte assez mal à l'élevage en batterie.

Les renseignements fournis par les 4 expériences concernent l'influence du poids initial des poulettes, les besoins en énergie, méthionine et lysine, et enfin le rôle propre du gène $d w$ sur le besoin en méthionine.

Dans les essais I et 2 le poids des poulettes à $\mathrm{r} 6$ semaines a varié de $\mathrm{I}, 3$ à I,5-I, $6 \mathrm{~kg}$ et, malgré un accroissement de poids plus marqué durant la période de ponte chez les animaux les plus légers, cette différence pondérale ne s'est pas annulée. Les poulettes les plus légères au départ ont pondu des œufs plus petits, et si l'on excepte l'essai no $\mathrm{I}$ où elles ont souffert davantage de la maladie de Marek, leur intensité de ponte a été plus élevée et leur efficacité alimentaire nettement meilleure. Tout cela confirme nos résultats antérieurs (GuILLAUME, I972a) mais on peut l'attribuer soit à des différences génétiques soit à des effets de milieu. En comparant des animaux dont le poids ne diffère que par suite du rationnement subi avant la ponte, on élimine le rôle de l'hétérogénéité génétique, Dans ces conditions, une différence de poids de $0,3 \mathrm{~kg}$ chez la poulette affecte très peu l'intensité de ponte et le poids moyen de l'œuf. Nous confirmons donc l'intérêt d'un rationnement sévère de la Vedette I.N.R.A. au-delà de l'âge de 6 semaines (LECLERCQ et BLUM, I972, I973, I975).

Nous démontrons surtout qu'il existe fort peu d'interactions entre taille corporelle et facteurs nutritionnels. Certes dans l'essai $n^{0} 2$ à la suite du rationnement les poules lourdes semblent pâtir davantage que les poules légères. Il apparaît toutefois que la différence de besoin énergétique entre poules lourdes et poules 
légères est très faible. Tout se passe comme si le supplément de besoin d'entretien des poules lourdes compensait le supplément de production d'œufs et de croît des poules légères.

Les essais $n^{0}$ I et 2 permettent de mieux situer le besoin énergétique de la JV I5. Étant donné la similitude des performances enregistrées dans les deux expériences, nous avons porté sur un même graphique la masse d'œufs produite en fonction de l'énergie métabolisable ingérée (fig. 3). Le besoin mesuré dans nos conditions se situe à $320-325 \mathrm{kcal} /$ animal et par jour. Cette valeur est supérieure à celle que nous avions citée antérieurement (GUILLAUME, I972a). I1 y a lieu d'attribuer cette divergence en partie à l'augmentation du poids corporel dû à la sélection génétique. On peut noter que cette valeur est voisine de celle $(308 \mathrm{kcal} / \mathrm{j})$

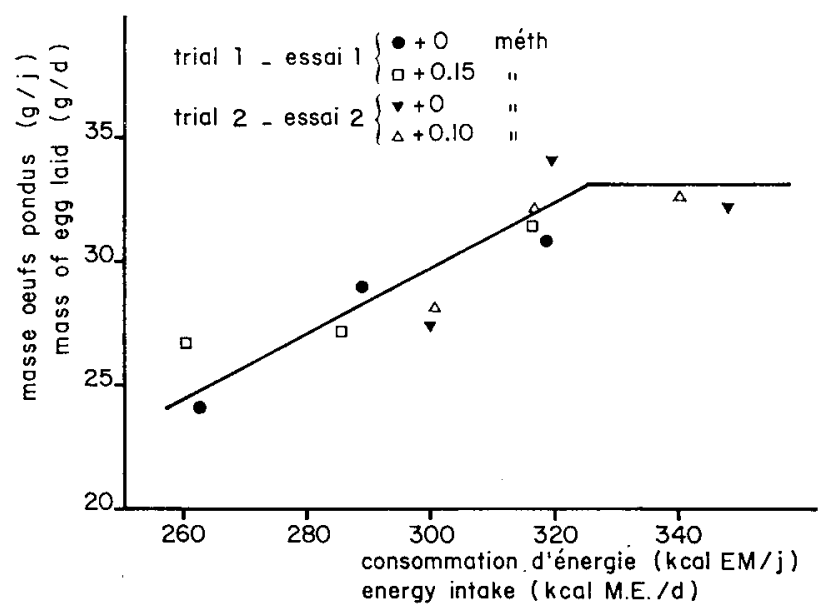

FIG. 3. - Relation entre ingéré énergétique

et masse d'oufs pondus par jour (estimation du besoin énergétique). Essais I et 2.

Relationship between energy intake and mass of egg laid/d (determination of energy requirement). Trials $I$ and 2 .

obtenue par HAZEN et WALDROUP, I97 I sur des reproductrices naines d'origine non précisée. Bougon (I975) a obtenu sur un croisement voisin de la Vedette I.N.R.A., une estimation de $360 \mathrm{kcal} / \mathrm{sujet}$ soit environ $325-330 \mathrm{kcal} /$ poule. La faible importance de ces besoins relativement au poids corporel est à rapprocher de l'action du gène dw sur le métabolisme énergétique (GulllaumE, I974, I975).

La supplémentation en DL méthionine a exercé des effets significatifs dans 3 des 4 essais effectués mais ces effets ne sont pas rigoureusement les mêmes chaque fois : l'apport de méthionine affecte la production de manière plus ou moins nette et à une période variable. De toute façon dès que la consommation dépasse $320 \mathrm{mg}$ de méthionine /j la production est améliorée d'une manière ou d'une autre. De plus, dans l'essai no 3 le poids moyen de l'œuf augmente nettement jusqu'à un ingéré de $365 \mathrm{mg} /$ jour et il est maximal chez les poules ingérant $425 \mathrm{mg} / \mathrm{j}$. Dans l'essai $\mathrm{n}^{\mathrm{o}} \mathrm{I}$, on voit, par ailleurs, que le poids initial des descendants de poules carencées en énergie peut être augmenté pour des consommations maternelles dépassant celle qui assure le poids moyen de l'œuf maximal.

D'un point de vue théorique, divers résultats appellent des commentaires : l'apparition des effets de la carence plus tardive dans le cas de la lysine que dans 
celui de la méthionine est à souligner. L'interaction entre méthionine et ration énergétique sur le poids d'œufs pondu observée dans les essais $n^{\circ}$ I et 2 est un fait inédit à notre connaissance, que nous ne pouvons interpréter à l'aide de ces seules observations. L'effet maternel de la méthionine observé dans l'expérience I est en accord avec celui, plus spectaculaire, que nous avions mis en évidence antérieurement : une surcharge de 0,15 p. Ioo de DL méthionine à un régime subcarencé a méliore le poids à la naissance et la croissance initiale du poussin descendant de la Vedette JV I5 (Guillaume, I972). Cet effet maternel peut s'expliquer, en partie du moins, par un accroissement de la proportion d'albumen dans l'œuf à la suite de l'apport de méthionine (Moran, I969; Leclerco, I970; Larbier, Blum et Guillaume, I972). Ce phénomène est aussi à rapprocher des résultats de Aitkes, Merritt et Curtiss (i 969) qui constatent une accélération de la croissance de la descendance après surcharge du régime maternel en protéine. II y aurait peut-être lieu de considérer, pour définir les besoins de la poule reproducductrice, en plus des critères usuels, le poids et la vitesse de croissance de la descendance.

L'essai $n^{\circ} 3$ bis apporte en outre des renseignements sur le rôle propre du gène $d w$. Les différences observées entre poules $d w$ et $D w$ sont conformes à ce que l'on sait sur l'action de ce gène (décrite par Guillaume 1976) à un détail près : les poules naines ont une maturité sexuelle plus précoce et non pas plus tardive que les poules normales. La réponse très nette de nos poules naines à la supplémentation en méthionine est en accord avec les résultats similaires obtenus par ARscotT et BERNIER, Ig68 et DAMRON et HARMS, I974 sur des Leghorn naines. On connaît mal le besoin en méthionine de la reproductrice lourde classique, les études de son besoin azoté se limitent en général aux protéines (Summers et al., I967, WARD, I969, OGATA et al., I972); on pourrait donc soupçonner nos régimes de base des essais I et 2 d'être carencés même pour une reproductrice normale. L'essai 3 bis montre cependant clairement qu'un supplément de méthionine a des effets différents dans les génotypes $D w$ et $d w$ : il augmente surtout le poids corporel dans le I er et le poids d'œufs pondus dans le second. On peut se demander si ce phénomène résulte d'un effet indirect du gène sur la taille corporelle (et par suite sur l'importance relative des besoins d'entretien et de ponte) ou d'un effet propre du gène sur le métabolisme protéique. Rappelons toutefois que le gène $d w$, chez le poussin en croissance, modifie le métabolisme protéique (Guillaume, I969, I972b; GuILlaume I975); chez la poule adulte les données sont plus rares, toutefois les travaux de Woor et al., I97 I indiquent bien une accélération du renouvellement de la méthionine chez la poule Leghorn $d w$. Tous ces faits sont bien en accord avec l'existence d'un besoin plus élevé en méthionine chez la poule $d w$ en ponte.

\section{Conclusion}

D'un point de vue pratique, l'ensemble de ces quatre essais permet de mieux situer les besoins de la Vedette I.N.R.A. JV I5 en ponte. Le besoin en méthionine est difficile à définir et il paraît possible d'utiliser des aliments à teneur variable selon les caractéristiques souhaitées par la production. Si l'on désire produire des poussins dont le poids à l'éclosion soit maximal ou si l'on désire stimuler au maximum la ponte durant les premières semaines de ponte, la dose de $360-380 \mathrm{mg} / \mathrm{j}$ peut être recommandée. Dans les mêmes conditions le besoin en lysine apparaît très voisin de $75^{\circ} \mathrm{mg} / \mathrm{j}$. Le besoin en énergie de la JV I 5 élevée en batterie de cages 
individuelles dans un local dont la température oscille entre 15 et $25^{\circ} \mathrm{C}$ est 320 325 kcal E.M. /j. Il est inutile d'adapter la composition de l'aliment et les doses distribuées en période de ponte au mode de rationnement suivi et au poids des poulettes à leur entrée en ponte.

Ces recommandations ne peuvent être considérées comme définitives : il importe en particulier de les vérifier dans des conditions d'élevage au sol où le besoin en énergie risque de différer notablement et de rechercher quelle est la consommation des coqs a fin de définir l'importance des rations à distribuer à chaque animal.

On peut constater que le besoin énergétique de la Vedette est faible comparé à celui d'une pondeuse d'œufs de consommation de type Rhode Island. Son besoin en protéines, exprimé en pourcentage de l'aliment, est inférieur à celui d'une Leghorn naine telle que celles étudiées par Arscot' et BerNier, rg68, Bernier et Arscott, I972; QUisenberry, I972, etc... En quantités quotidiennes, ces besoins sont un peu supérieurs à ceux d'une pondeuse classique. La Vedette I.N.R.A. JV I5 diffère donc de la Leghorn $d w$ par sa taille qui augmente l'importance des besoins énergétiques par rapport aux besoins protéiques; elle diffère de la pondeuse Rhode Island, de poids voisin et de production plus élevée sans doute à cause de l'effet propre du gène $d w$ qui modifie l'utilisation des protides et en particulier de la méthionine.

Reçu pour publication en janvier 1977.

\section{Summary}

\section{Further data on energy and amino acid requirements of the dwarf breeding hen (Vedette I.N.R.A. JV I5)}

Three experiments were carried out in meat type dwarf breeding hens, "Vedette I.N.R.A. J.V. I 5" (dw gene). All birds were reared in batteries of cages during a rather short period (20 to 32 weeks), fed and controlled individually. Another trial concerned hens from an experimertal crossing (heterozygote cock $\times$ dwarf hen) where $50 \%$ of hens were normal sized and $50 \%$ dwarf. The effect of food restriction during the growth period and the body weight were analysed. First of all the influences of energy, methionine and lysine intake on performances were studied. The effect of energy deficiency appeared to be different in heavy and in light hens (egg weight and egg number were reduced in heavy birds while only egg weight was reduced in light ones), but the interactions between dietary factors and body size were rather smallFood restriction during the growing period did not modify the food requirements during the laying period. The effect of a deficiency in lysine appeared later than that of a deficiency in methionine. The intake of amounts of methionine exceeding $320 \mathrm{mg} / \mathrm{bird} / \mathrm{d}$ had always some beneficial effects. But they were not the same in each experiment: either laying performances were improved during the first 8 weeks of laying only or mean egg weight was increased during the whole trial. Furthermore, supplementation of maternal diet with methionine increased chick weight at hatching. However, the effect of methionine supplementation appeared much more pronounced in hens most deficient in energy.

Although the methionine requirement was difficult to measure, the following values may be given: 360 to $380 \mathrm{mg} / \mathrm{hen} / \mathrm{d}$. In our conditions, requirements for energy and lysine were close to $320 \mathrm{kcal} \mathrm{ME}$ and $75^{\circ} \mathrm{mg} / \mathrm{hen} / \mathrm{d}$, respectively.

The effects of the dwarfing gene itself on nutrient requirements and mainly on methionine requirement are discussed.

\section{Références bibliographiques}

Axonyme, I972. Recommandations industrielles en alimentation animale, énergie, acides aminés, minéraux, vitamines. Document technique no I I A. A.C. 03400 Commentry (France).

Aitken J. R., Merritt E. S., Curtiss R. J., I969. The influence of maternal diet on egg size and progeny performances in meat type hens. Poult. Sci., 48 , 596-601. 
Arscott G. M., Bernier P. E., 1968. Effect of dietary protein on performance of dwarf white Leghorn layers. Poult. Sci., 47, 1652 (Abstr.).

Bernier P. E., Arscott G. M., 1972. Fifteen years of observations on the dwarf gene in the domestic fowl. Ann. Gén. sél. anim., 4, 183-213.

Bougon M., I975. (Communication personnelle.)

Damron B. L., HARms R. H., I974. Evaluating the performance and sulphur aminoacid requirements of normal and midget hens. Brit. Poult. Sci., I5. 535-540.

Guillaume J., 1969. 'Conséquences de l'introduction du gène de nanisme $d w$ sur l'utilisation alimentaire chez le poussin femelle. Ann. Biol. anim. Bioch. Biophys., 9, 369-378.

Gurllaume J., i972a. Données complémentaires sur les besoins nutritionnels de la reproductrice naine Vedette I.N.R.A. JV 15. Ann. Génét. Sél. anim., 4, 281-295.

Guillaume J., 1972b. Quelques particularités nutritionnelles et physiologiques du poussin nain dw. Ann. Génét. Sél. anim., 4, 233-250.

Gurllaume J., 1974. Effets du gène de nanisme récessif et lié au sexe dw sur le métabolisme énergétique de la poule. Energy metabolism of farm animals E.A.A.P. publ. 14, 269-272.

Guillaume J., I975. Recherche sur les caractéristiques nutritionnelles et métaboliques du poussin nain dw (metabolismes énergétique lipidique et protidique). Thèse Doc. État, Université de Tours, Janvier 1975 .

Guillaume J., I976. The dwarfing gene $d r e$ its effects on anatomy physiology, nutrition, managements, its application in poultry industry. Wordl's Poult. Sci. J., 32, 285-304.

Hazen K. R., Waldroup P. W., I971. Caloric intake restriction of dwarf broiler breeders. Poult. Sci., 50, ${ }_{5} 85$ (Abstr.).

Hutt F. B., 1959. Sex-linked dwarfism in the fowl. J. Heredity, 50, 209-22I.

Hutt F. B., I949. In , Genetics of the fowl". 263-264. Mc Gray Hill Book Company, New-York.

Larbier M., Blum J. C., Guillaume J., 1972. Effets d'une déficience alimentaire en lysine et méthionine sur les performances de ponte et sur la teneur en acides aminés libres du j.une d'œuf. Ann. Biol. anim. Bioch. Biophys., I2, I25-138.

LECLERCQ B., I97o. Facteurs nutritionnels modifiant le poids de l'œuf et de ses constituants. Ann. Biol. anim. Bioch. Biophys., Io, 239-252.

LeclercQ B., Guillaume J., Blum N. C., I970. Données sur les besoins alimentaires de la reproductrice naine Vedette I.N.R.A. (dw) durant les périodes de croissance et de ponte. Proc. XIV Cong. Mondial d'Avicultuve, Madrid, sept. 1971, 787-795.

LeClerco B., Blum J. C., 1972. Effet de diverses restrictions alimentaires chez la poule reproductrice naine sur les performances de ponte. Ann. Génét. Sél. anim., 8, 259-27o.

Leclerco B., Blum J. C., I973. Étude de l'alimentation de la poulette : interaction entre mode de restriction, gène de nanisme et type de pondeuse. $J$. Rech. avic. cunic., Paris, (Publ. I.T.A.V.I.), 2 II I-2I 5 .

LECLERCQ B., BLUM J. C., 1975. Restricted feeding of growing pullets - interaction between the method of restriction and the dwarfism gene $(d w)$. Avch. Gefkde, 3r, I53-158.

Moran E. T., I 969 . Levels of dietary protein needed to support egg weight and laying hen production. Feedstuffs, 81 (n⿳⺈ 22), 26-28.

Ogata K., Mizogami I., Matori K., Kashiwagi S., 1972. Studies on the layer diet for meat type breeding hen. I optimum level of dietary protein. Jap. Poult. Sci., 9, 46-50.

Quisenberry J. H., 1972. High density diets for dwarf layers. Ann. gen. sel. anim., 4, 27 I-279.

RICARD F. H., 1974. Étude du gène de nanisme $d w$ pour la production du poulet de chair. $X I I$ th Symposium Cientifico y assemblea general anual. Publ. branche espagnole de la W.P.S.A. (sous presse).

SNedecor G. W., Cochran W. G., I97I. Méthodes statistiques (trad. françaises de H. Boelle et E. Camhaji . A.C.T.A. Ed. Paris.

Summers J. D., Pepper W. F., Slinger S. J., Mc Conachie J. D., i967. Feeding meat type pullets and breeders. I methods for and significance of lowering the live weight of meat type pullets at point of lay. 2 evidence on the protein and energy needs of meat type breeders. Poult. Sci., 46, II 58.

Ward J. B., I969. Phase feeding of broiler breeder hens. Poult. Sci., 48, 1888-1889 (Abstr.).

Wood A. S., Brown R. G., Summers J. D., Reinhart B. S., 1971. An aspect of protein biosynthetic activity by the dwarf and non-dwarf white Leghorn chicken. Poult. Sci., 50, 982-984. 